\title{
THERMAL CYCLING CREEP RESISTANCE OF Ni-BASED SINGLE CRYSTAL SUPERALLOYS
}

\author{
Jonathan CORMIER \\ Institut Pprime - UPR CNRS 3346; ISAE-ENSMA \\ 1 Avenue Clément Ader; BP 40109; 86961 Futuroscope Chasseneuil; France
}

Keywords: Single crystal Ni-based superalloys, Thermal cycling, Creep, Microstructure Stability

\begin{abstract}
This paper reviews the non-isothermal creep resistance of $\mathrm{Ni}$ based single crystal superalloys. For this, the creep resistance under very high temperature thermal cycling conditions of ten different $<001>$-oriented Ni-based single crystal superalloys from the first to the fourth generation has been investigated. Thermal cycling creep experiments consist of repeated short overheatings at $1105{ }^{\circ} \mathrm{C}$ and $1160{ }^{\circ} \mathrm{C}$ applied during a creep test at $1050{ }^{\circ} \mathrm{C} / 120 \mathrm{MPa}$. Such thermal cycling conditions are representative of the most damaging stages of the certification procedures of small gas turbines in which creep is a life limiting factor for uncooled blades.

It is shown that the creep resistance under such non-isothermal creep conditions is primarily controlled by the $\gamma^{\prime}$ volume fraction remaining at high temperature, especially during the temperature spikes at $1160{ }^{\circ} \mathrm{C}$. Indeed, higher $\gamma^{\prime}$-solvus alloys exhibit better creep resistance under such thermal cycling conditions. It is also shown that increasing the rhenium content does not necessarily results in a better thermal cycling creep resistance and that having a good $\gamma^{\prime}$ morphological stability (i.e. slow $\gamma^{\prime}$ rafting kinetics and $\gamma / \gamma^{\prime}$ topological inversion) results in a better non-isothermal creep life. From the present experimental characterization, some guidelines for the development of non-isothermal creep resistant alloys are presented.
\end{abstract}

\section{Background and motivations}

Ni-based single crystal superalloys are nowadays widely used for the design and manufacturing of blades and vanes of the hottest sections of aero-engines and industrial gas turbines [1]. Several generations of such alloys have been developed to increase the temperature capability in terms of creep resistance, adding rhenium and/or ruthenium as main alloying elements [2-4]. One of the key stages for original engine makers in the development of a new gas turbine for aircraft or helicopter applications is to pass the certification procedures imposed by the airworthiness authorities (e.g., FAA in the USA or EASA in Europe). Such certification procedures are generally composed of various engine tests, including endurance tests and/or accelerated simulated mission engine tests (ASMET). As observed in Fig. 1, a very complex temperature and stress history is encountered during such a certification engine test. They are indeed designed to mimic the different regimes that can be encountered during a common flight (e.g. take off, cruise, landing), but also during emergency events leading to unusual regimes highlighted in Fig. 1 by arrows. Such cycles generally represent One Engine Inoperative (OEI) conditions encountered in the remaining operating engine(s) of aircraft or twin-engine helicopters [5]. These emergency conditions are critical to the blade material resistance since the metal temperature is very close to the $\gamma^{\prime}$-solvus of the alloy in several sections, typically over $1150{ }^{\circ} \mathrm{C}$ [5-10]. These extreme temperature exposures are short (typical OEI regimes are 30 or 150 seconds) but, as illustrated in Fig. 1 or in a previous paper from Mauget et al. [6], they can be repeated several times. Hence, characterizing the creep resistance under thermal cycling (noted as $\mathrm{TC}$ in this paper) conditions is a key issue to avoid any failure or catastrophic elongation of uncooled components (such as high pressure blades of low and medium power turboshaft engines for helicopters or thin walled blades of low pressure turbine stages of large turbofan engines) during the certification procedures.

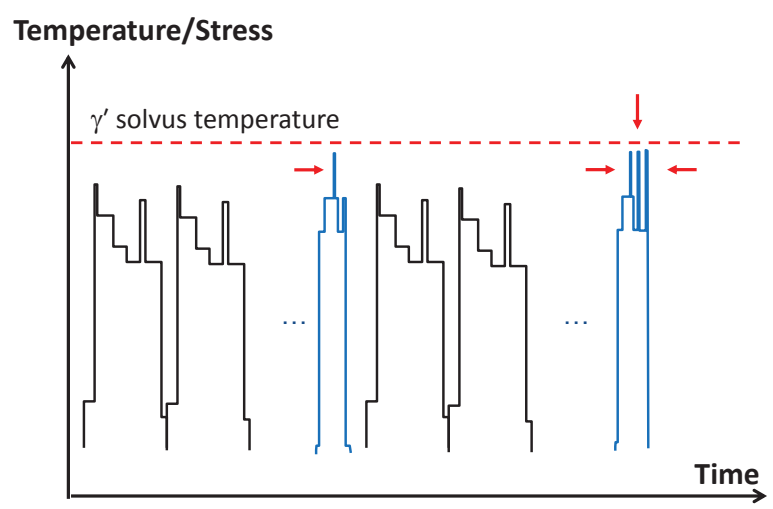

Figure 1. Typical temperature/stress profile during an ASMET (Accelerated Simulated Mission Engine Test) certification procedure. Temperature peaks close to the $\gamma^{\prime}$-solvus of the blade alloy are highlighted by arrows.

In the past, very few studies have been focused on the characterization of the non-isothermal creep resistance of $\mathrm{Ni}$ based superalloys. Pioneering studies were undertaken at NACA (National Advisory Committee for Aeronautics, former name of the NASA) late in the 50's by Rowe and Freeman [11-15] and then in the 70's by Weiss et al. at Technion, Israël $[16,17]$. These studies used equiaxed polycrystalline Ni-based alloys with low to moderate volume fractions of strengthening particles (e.g. Udimet 500 in the studies of Weiss et al.) and periodic temperature peaks were introduced in the creep life at a nominal temperature. As a main result of these studies, a faster creep strain rate under thermal cycling conditions was observed compared to that obtained at the nominal isothermal creep conditions. Moreover, it was shown that there was no possibility to calculate the thermal cycling creep life based on isothermal creep databases, since transient changes in the creep strain rate occurred during and just after each overtemperatures. Very first studies on the TC creep resistance of Ni-based single crystal superalloys (MC2 and CMSX-4® alloys) were performed later in France in two different research groups at Cirimat - ENSIACET, Toulouse [18-21] and Institut Pprime, ISAE-ENSMA, Poitiers [22-29], with a continuous support of SAFRAN-Turbomeca. While TC 
experiments performed at Cirimat consist of periodic "underheatings" in the course of a very high temperature creep test (mostly at $1150{ }^{\circ} \mathrm{C}$ ), the conditions studied at Institut Pprime consist of periodic overheatings introduced in the high temperarture/low stress creep life (mostly at $1050{ }^{\circ} \mathrm{C}$ ) of the alloys. Specific test benches were developed in both groups to perform such complex experiments. Burner rigs were even developed at Institut Pprime (such as the MAATRE burner) to simulate service conditions and to generate engine tests spectra [6, 9], like the one presented in Fig. 1. As a common result from all these studies, a faster strain rate and higher creep strain at the secondary to tertiary creep stages transition under TC conditions compared to pure isothermal conditions were observed $[18,19$, $21,23,25,28]$, even considering the highest temperature level during thermal cycling for Institut Pprime loading conditions [25]. This faster strain rate under non-isothermal conditions has been correlated to a faster degradation of the $\gamma^{\prime}$ structure (i.e. $\gamma^{\prime}$-rafting) compared to pure isothermal conditions $[18,21]$ and to an easier penetration of dislocations inside $\gamma^{\prime}$ particles during cooling $[22,24]$. Moreover, coarsened and N-type $\gamma^{\prime}$-rafted microstructure have been shown to be less thermal cycling creep resistant in comparison to the classical $\gamma-\gamma^{\prime}$ cuboidal microstructure $[23,25,28]$. This can be explained both by a faster $\gamma^{\prime}$ dissolution [30] and again, by an easier penetration of dislocations inside the $\gamma^{\prime}$-phase. However, no extensive study screening various alloy chemistries, has been undertaken up to now to investigate the key microstructural factor(s) controlling the non-isothermal creep properties. This is the main aim of this paper, whose additional final objective is to propose some guidelines to select/develop creep resistant alloys under such extreme conditions.

\section{Experimental techniques}

\section{$\underline{\text { Materials and creep samples }}$}

In this study, the TC resistance of ten different Ni-based single crystal superalloys from the first to the fourth generation has been investigated. They were casted using a standard Bridgman process. Their chemical composition is listed in Table I. The newly developed CMSX-4® Plus alloy [31, 32] has been classified as a third generation alloy according to its chemistry (see Table I). Creep specimens were machined out by spark plasma erosion from bars or plates which were provided by SAFRAN-Snecma, SAFRAN-Turbomeca, GE Global Research and Cannon Muskegon Corporation. Before machining, each bar/plate had received the standard solution and aging heat treatments designed for aero-engine or industrial gas turbine applications (see Table II). These specific heat treatments formed a classical cuboidal $\gamma / \gamma^{\prime}$ microstructure with $\gamma^{\prime}$ precipitates having an average $0.4-0.55 \mu \mathrm{m}$ edge length. Samples were machined close to a $<001>$ crystallographic orientation, with a primary misorientation less than $5^{\circ}$ with respect to the stress axis. Creep samples had a $14 \mathrm{~mm}$ gage length and a $4 \mathrm{~mm}$ gage diameter [28]. Before creep testing, they were low stress mechanically polished up to a $4000 \mathrm{SiC}$ paper. Final polishing was performed parallel to the stress axis.

\section{Creep testing}

Tension creep tests have been performed using a radiant furnace, allowing fast heating/cooling rates. This creep test rig is equipped with a contactless extensometer to avoid any perturbation of the temperature distribution of the specimens during temperature changes. The TC conditions chosen in this study are shown in Fig. 2. They consist of repeated one minute long overheatings at $1105^{\circ} \mathrm{C}$ and $1160{ }^{\circ} \mathrm{C}$ introduced alternatively each 15 minutes in the creep life of the alloys at $1050{ }^{\circ} \mathrm{C} / 120 \mathrm{MPa}$. Whatever the overheating temperature, heating and cooling rates were fixed at $2{ }^{\circ} \mathrm{C} / \mathrm{s}$ and $10^{\circ} \mathrm{C} / \mathrm{s}$, respectively. Each creep curve has been postprocessed to remove variations in thermal and elastic strain resulting from thermal cycling. The interested reader is referred to [28] for additional experimental details. One to five TC creep experiments per alloy were performed. Isothermal creep tests were also performed at $1160{ }^{\circ} \mathrm{C} / 120 \mathrm{MPa}$ up to failure to better analyze the non-isothermal creep resistance of the alloys. To reduce scatter in experimental results, all the experiments (both isothermal and anisothermal ones) were performed using the same creep equipment.

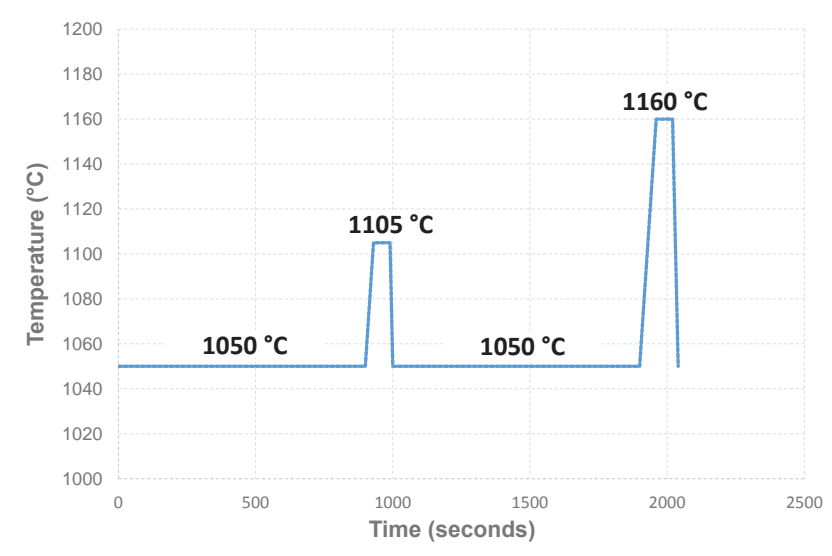

Figure 2. Thermal cycle applied during TC creep experiments at $120 \mathrm{MPa}$.

\section{Microstructure and physical properties characterization}

The $\gamma / \gamma^{\prime}$ microstructure after TC creep experiments has been observed by scanning electron microscopy (SEM). After failure, longitudinal sections of the samples and subsequent mechanical polishing up to a mirror finish ( $1 \mu \mathrm{m}$ diamond spray) were performed. The $\gamma^{\prime}$ microstructure was revealed by selective dissolution of the $\gamma^{\prime}$ phase by immersion in a solution made of $33 \% \mathrm{HNO}_{3}$ and $67 \% \mathrm{HCl}$ (vol. pet), at $4{ }^{\circ} \mathrm{C}$ for 8 seconds. Observations were performed using the secondary electron imaging mode of a JEOL JSM ${ }^{\circledR} 7000 \mathrm{~F}$ field emission gun SEM operating at $25 \mathrm{kV}$. Stereological characterizations were performed using the Visilog software and specific algorithms developed at Institut Pprime [33]. Both $\gamma^{\prime}$ area fraction, $\gamma^{\prime}$ particles average dimensions (length, thickness) and $\gamma / \gamma^{\prime}$ connectivity number [34] have been determined after testing up to failure in each specimen, using 5 pictures at least.

The $\gamma^{\prime}$-solvus temperatures of each alloys presented in Table I were either extracted from the literature for Mar-M200 + Hf and CMSX ${ }^{\circledR}-10 \mathrm{~K}[35,36]$, from ONERA results for AM1, AM3 and MCNG [37, 38], from our own experiments for MC2 and CMSX$4{ }^{\circledR}[25,30,39]$ and from DSC experiments performed by the Cannon Muskegon Corporation for CMSX-4® Plus alloy [32]. An example of such a determination using a DSC experiment is presented in Fig. 2. 
Table I. Chemical Compositions of Alloys (Wt. \%)

\begin{tabular}{|c|c|c|c|c|c|c|c|c|c|c|c|c|c|c|c|c|c|}
\hline \multirow{2}{*}{ Alloy } & \multirow{2}{*}{ Provider } & \multirow{2}{*}{ Solvus $\left({ }^{\circ} \mathrm{C}\right)$} & \multirow{2}{*}{ Density $\left(\mathrm{g} / \mathrm{cm}^{3}\right)$} & \multirow{2}{*}{ Gen. $^{\circ}$} & \multicolumn{13}{|c|}{ Composition (wt \%) } \\
\hline & & & & & $\mathrm{Ni}$ & Co & $\mathrm{Cr}$ & Mo & $\mathbf{W}$ & $\mathrm{Ta}$ & $\mathrm{Al}$ & $\mathrm{Ti}$ & $\operatorname{Re}$ & $\mathbf{R u}$ & $\mathrm{Hf}$ & $\mathrm{Nb}$ & Others \\
\hline René N4 & GE Global Research & $1230+/-10$ & 8.56 & \multirow{3}{*}{1} & \multirow{3}{*}{ Bal. } & 7.5 & 9.8 & 1.5 & 6.0 & 4.8 & 4.2 & 3.5 & 1 & 1 & 0.13 & 0.50 & $0.05 \mathrm{Si}$ \\
\hline AM1 & Snecma & $1268+/-5$ & 8.59 & & & 6.5 & 7.8 & 2.0 & 5.7 & 7.9 & 5.2 & 1.1 & 1 & 1 & 1 & 1 & 1 \\
\hline MC2 & Turbomeca & $1265+/-5$ & 8.63 & & & 5.0 & 8.0 & 2.0 & 8.0 & 6.0 & 5.0 & 1.5 & 1 & 1 & 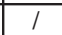 & 1 & 1 \\
\hline René N5 & GE Global Research & $1270+/-5$ & 8.63 & \multirow[b]{2}{*}{2} & \multirow{2}{*}{ Bal. } & 7.5 & 7.0 & 1.5 & 5.0 & 6.5 & 6.2 & $\frac{1}{1}$ & 3.0 & $\frac{1}{1}$ & 0.15 & $\frac{1}{1}$ & $0.05 \mathrm{C} \& 0.01 \mathrm{Y}$ \\
\hline CMSX-4 & Cannon Muskegon & $1293+/-7$ & 8.70 & & & 9.7 & 6.4 & 0.6 & 6.4 & 6.5 & 5.6 & 1.1 & 2.9 & 1 & 0.10 & 1 & 1 \\
\hline MCNG & Turbomeca & $1293+/-2$ & 8.75 & 4 & Bal. & $\frac{1}{1}$ & 4.0 & 1.0 & 5.0 & 5.0 & 6.0 & 0.5 & 4.0 & 4.0 & 0.10 & 1 & $0.1 \mathrm{Si}$ \\
\hline
\end{tabular}

Table II. Heat Treatment Conditions of Alloys

\begin{tabular}{|c|c|c|}
\hline Alloy & Solution Heat Treatment & Aging Treatment \\
\hline Mar-M200+Hf & $1210^{\circ} \mathrm{C} / 0.5 \mathrm{~h}+1225^{\circ} \mathrm{C} / 0.5 \mathrm{~h}+1240^{\circ} \mathrm{C} / 4 \mathrm{~h} / \mathrm{GFC}$ & $1100{ }^{\circ} \mathrm{C} / 5 \mathrm{~h} / \mathrm{AQ}+870^{\circ} \mathrm{C} / 16 \mathrm{~h} / \mathrm{AQ}$ \\
\hline AM1 & $1300{ }^{\circ} \mathrm{C} / 3 \mathrm{~h} / \mathrm{AQ}$ & $1100{ }^{\circ} \mathrm{C} / 5 \mathrm{~h} / \mathrm{AQ}+870{ }^{\circ} \mathrm{C} / 16 \mathrm{~h} / \mathrm{AQ}$ \\
\hline René N5 & Fully Solutioned - Solution Heat Treatment Condifential to GE Global Research & $\begin{array}{c}1120^{\circ} \mathrm{C} / 4 \mathrm{~h} / \mathrm{AQ}+1080^{\circ} \mathrm{C} / 6 \mathrm{~h} / \mathrm{AQ} \\
+870{ }^{\circ} \mathrm{C} / 16 \mathrm{~h} / \mathrm{AQ}\end{array}$ \\
\hline CMSX-4® & $\begin{aligned} & 1277{ }^{\circ} \mathrm{C} / 2 \mathrm{~h}+1288^{\circ} \mathrm{C} / 2 \mathrm{~h}+1296^{\circ} \mathrm{C} / 3 \mathrm{~h}+1304^{\circ} \mathrm{C} / 3 \mathrm{~h}+1313^{\circ} \mathrm{C} / 2 \mathrm{~h} \\
&+1316^{\circ} \mathrm{C} / 2 \mathrm{~h}+1318^{\circ} \mathrm{C} / 2 \mathrm{~h}+1321{ }^{\circ} \mathrm{C} / 2 \mathrm{~h} / \mathrm{GFC} \\
&\end{aligned}$ & $1140{ }^{\circ} \mathrm{C} / 6 \mathrm{~h} / \mathrm{AQ}+871^{\circ} \mathrm{C} / 20 \mathrm{~h} / \mathrm{AQ}$ \\
\hline CMSX ${ }^{\circledR}-10 \mathrm{~K}$ & $\begin{array}{r}1315^{\circ} \mathrm{C} / 1 \mathrm{~h}+1329^{\circ} \mathrm{C} / 2 \mathrm{~h}+1335^{\circ} \mathrm{C} / 2 \mathrm{~h}+1340^{\circ} \mathrm{C} / 2 \mathrm{~h}+1346^{\circ} \mathrm{C} / 2 \mathrm{~h} \\
+1352^{\circ} \mathrm{C} / 3 \mathrm{~h}+1357{ }^{\circ} \mathrm{C} / 3 \mathrm{~h}+1360^{\circ} \mathrm{C} / 5 \mathrm{~h}+1363^{\circ} \mathrm{C} / 10 \mathrm{~h}+1365^{\circ} \mathrm{C} / 15 \mathrm{~h} / \mathrm{GFC}\end{array}$ & $1152{ }^{\circ} \mathrm{C} / 6 \mathrm{~h} / \mathrm{AQ}+871^{\circ} \mathrm{C} / 24 \mathrm{~h} / \mathrm{AQ}$ \\
\hline MCNG & $1310^{\circ} \mathrm{C} / 3 \mathrm{~h} / \mathrm{h}$ eating at $3{ }^{\circ} \mathrm{C} / \mathrm{h}+1340^{\circ} \mathrm{C} / 4 \mathrm{~h} / \mathrm{GFC}$ & $1100{ }^{\circ} \mathrm{C} / 4 \mathrm{~h} / \mathrm{AQ}+870^{\circ} \mathrm{C} / 16 \mathrm{~h} / \mathrm{AQ}$ \\
\hline
\end{tabular}

*AQ = Air Quench, GFC = Gas Furnace Cooling

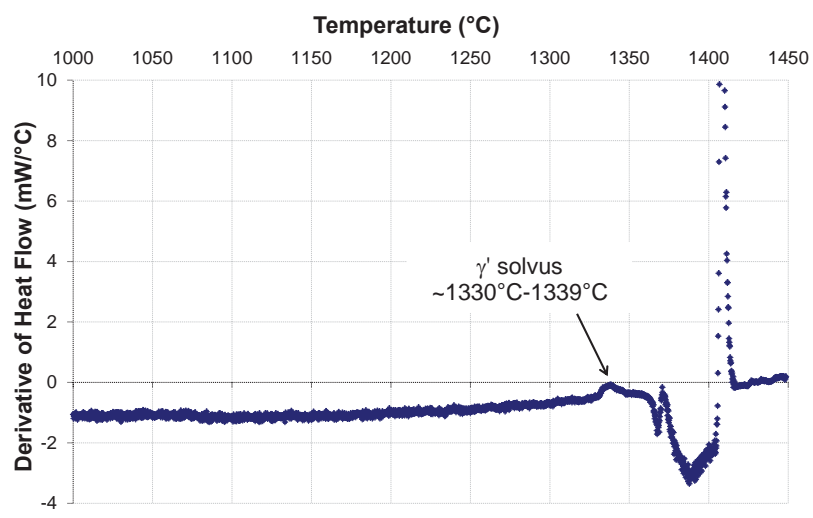

Figure 3. Derivative of the heat flow during a DSC experiment used to determine the $\gamma^{\prime}$-solvus temperature of CMSX-4® Plus alloy on heating.

\section{Experimental results}

Isothermal creep behavior at very high temperature

The isothermal creep curves at $1160{ }^{\circ} \mathrm{C} / 120 \mathrm{MPa}$ for all alloys, except MCNG, are shown in Fig. 4. This creep testing condition has been chosen since temperature spikes at $1160{ }^{\circ} \mathrm{C}$ are introduced periodically in the creep life of the alloys at 1050 ${ }^{\circ} \mathrm{C} / 120 \mathrm{MPa}$ (see Fig. 2) and since it is the hottest conditions of the thermal cycle. It will hence generate most of the creep elongation and damage during TC creep experiments. As observed in Fig. 3, the creep curves of AM3, AM1, MC2, René N5, CMSX-4®, CMSX-4® Plus and CMSX ${ }^{\circledR}-10 \mathrm{~K}$ are typical of the $\gamma^{\prime}$ rafting regime as defined by Reed et al [4], with a very limited primary creep stage corresponding to the $\gamma^{\prime}$ rafting process, a well-defined secondary creep stage and a steep tertiary creep stage corresponding to creep strain localization [40]. Under these extreme creep conditions, it is also observed that Mar-M200 + Hf and René N4 exhibit very poor creep resistance, with creep lives of respectively 3 and 46 minutes and no clearly defined steady-state creep stage. Under this creep condition, the creep life of the stronger alloy (CMSX $\AA-10 \mathrm{~K})$ is $\sim 1500$ times longer than the weakest one (Mar-M200 + Hf).

Thermal cycling creep behavior

Figure 5 compares the TC creep resistance of the alloys investigated in this study. For the sake of clarity, only one creep curve for each alloy has been kept to lighten this figure. For most of the alloys, except CMSX-4® Plus and CMSX ${ }^{\circledR}-10 \mathrm{~K}$, the creep curves are characterized by "steps" corresponding to each creep strain jump induced by one single overheating. These plastic strain jumps are especially observed for temperature peaks at $1160{ }^{\circ} \mathrm{C}$ and almost no strain jump is observed for overheatings at $1105^{\circ} \mathrm{C}$, except at the very end of the tests in the tertiary creep stages. This strain increment during temperature dwell at $1160{ }^{\circ} \mathrm{C}$ is spectacular for Mar-M200 + Hf alloy (see Fig. 5b, black curve) due to its very low creep resistance at $1160{ }^{\circ} \mathrm{C} / 120 \mathrm{MPa}$ (see Fig. 4b). All these observations are in good agreement with past studies $[25,28]$. Contrary to all other alloys, almost no creep strain jumps are observed for CMSX-4® Plus and CMSX ${ }^{\circledR}-10 \mathrm{~K}$ during most of their TC creep life (see Fig. 5), except at the very end of the test. This is clearly related to their very high creep strength at $1160{ }^{\circ} \mathrm{C} / 120 \mathrm{MPa}$ (Fig. 4) compared to the other first and second generation alloys. 

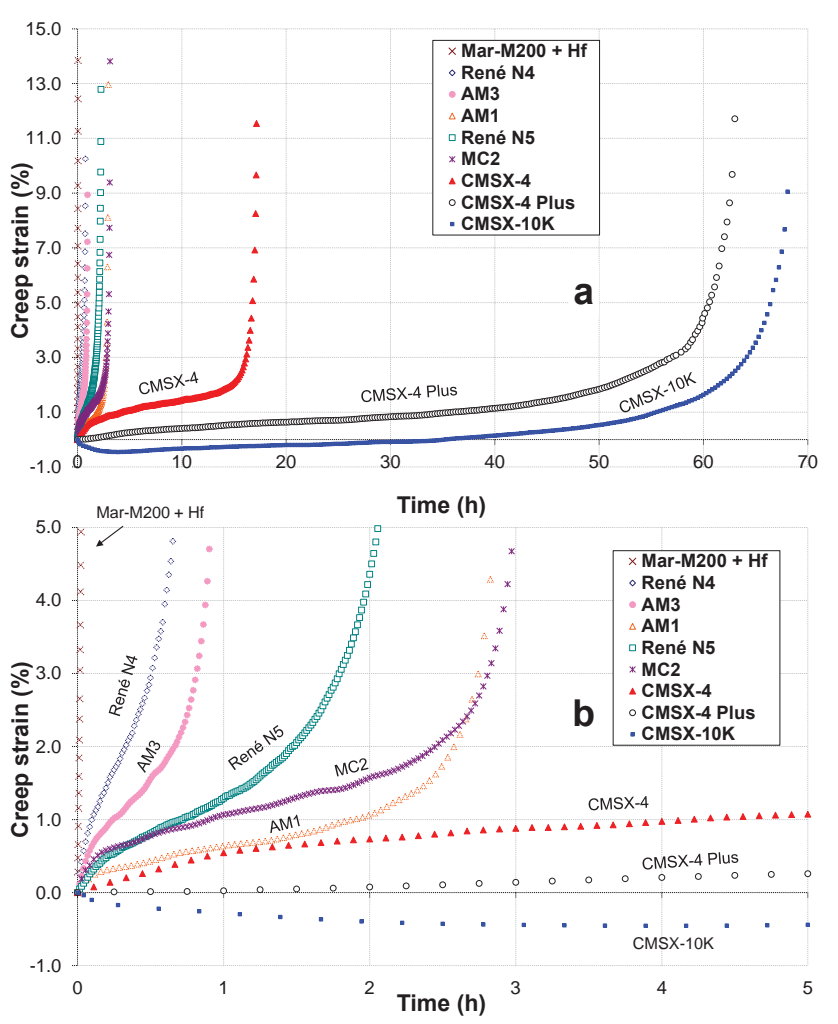

Figure 4. Isothermal creep curves at $1160{ }^{\circ} \mathrm{C} / 120 \mathrm{MPa}$ in full time scale (a) and magnification on the first five hours of creep (b).

For this specific temperature history, a huge variation in creep life, by a factor of nearly 160 between Mar-M200 + Hf and CMSX ${ }^{\circledR}-10 \mathrm{~K}$ was observed. This reduced difference in time to failure (or number of thermal cycles to failure) results from the fact that temperature overheatings at $1160^{\circ} \mathrm{C}$ only account for $3 \%$ of the thermal cycle (see Fig. 2) and creep damage can also develop during the lower temperature states of the tests. It has also to be noted that failure always occurred during an overheating at $1160{ }^{\circ} \mathrm{C} / 120 \mathrm{MPa}$, whatever the material and sample. Hence, $\gamma / \gamma^{\prime}$ microstructure observations that will be presented in the next section will be comparable.

\section{$\underline{\text { Microstructure observations }}$}

Microstructure observations were performed after failure in each alloy. Figure 6 shows selected SEM observations, both at low magnification to show the general features of the non-isothermal creep failure and at higher magnification to show the typical $\gamma / \gamma^{\prime}$ microstructure. Three alloys representative of a low (René N4), medium (CMSX-4 $\left.{ }^{\circledR}\right)$ and high TC creep strength (CMSX $\left.{ }^{\circledR}-10 \mathrm{~K}\right)$ alloy were chosen. As a common observation for Mar-M200 + Hf, AM3, MC2 and René N4, a very pronounced strain localization is observed close to failure. For CMSX-4®, CMSX-4®-Plus, MCNG and CMSX ${ }^{\circledR}-10 \mathrm{~K}$, the situation is quite different, with a more homogeneous elongation all along the gage length of each specimens (see upper pictures of Fig. 6 for CMSX-4® and CMSX $\left.{ }^{\circledR}-10 \mathrm{~K}\right)$. The creep failure always occurs by a coupled creep strain accumulation-cavitation process. It is observed qualitatively in Fig. 6 an increased fraction of opened pores close to failure, in the necking area of the samples, especially for René N4 and CMSX-4®.
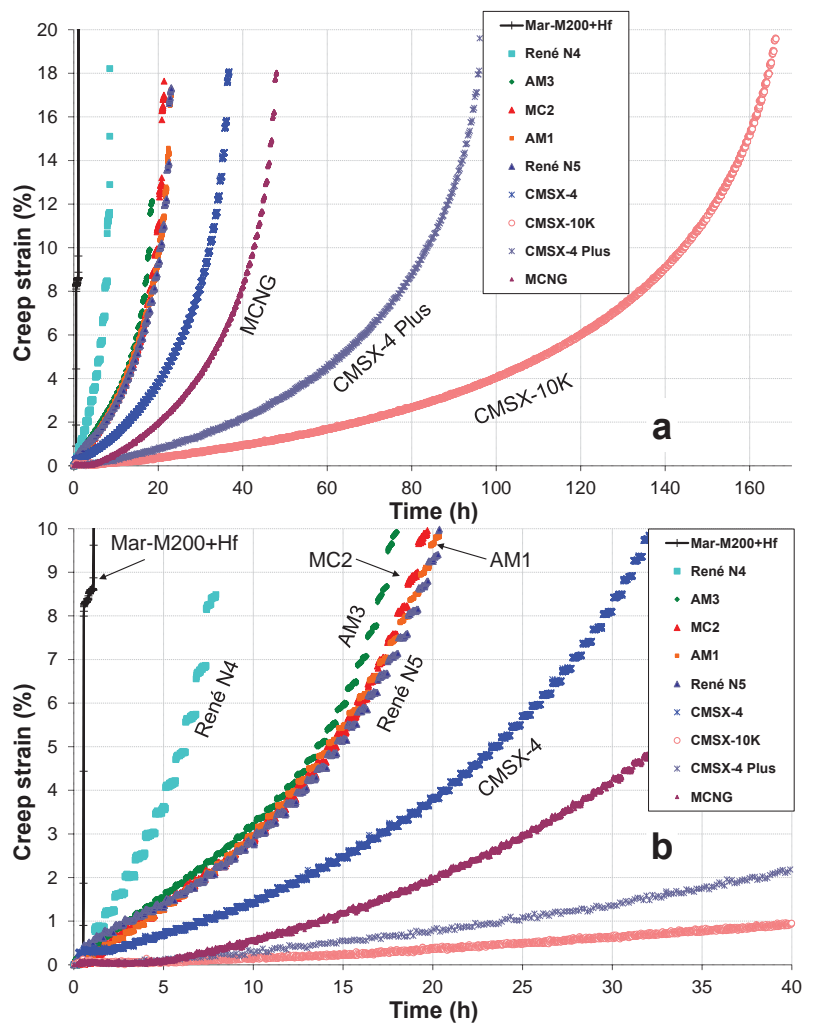

Figure 5. Thermal cycling creep curves in full time/strain scales (a) and magnification on the first 40 hours/10\% of creep strain (b).

For the strongest alloys like CMSX-4® Plus and CMSX ${ }^{\circledR}-10 \mathrm{~K}$, smaller pores leading to crack initiation are evenly distributed within the gage volume. They are mainly nucleating close to the remaining eutectics as observed in Figure 7. Even if these alloys present the highest TC creep resistance, reducing the amount of remaining eutectics would probably further increase their creep resistance, by increasing the amount of "efficient" $\gamma^{\prime}$ particles and by retarding pore nucleation.

According to Fig. 6, a rafted $\gamma^{\prime}$ microstructure is observed in all alloys after failure. This lamellar structure is more regular far from the fracture surface (see third line of pictures in Fig. 6, corresponding to observations $5 \mathrm{~mm}$ away from the fracture) in comparison to $1 \mathrm{~mm}$ away from failure (see second line of pictures in Fig. 6). This results from the increase in stress triaxiality in the later stages of creep deformation when strain localization occurs [40]. It is also observed qualitatively in Fig. 6 an increase in $\gamma^{\prime}$ content from René N4 up to CMSX ${ }^{\circledR}-10 \mathrm{~K}$, as well as an increased number of connections between $\gamma^{\prime}$ rafts. Figures 7 and 8 provide quantitative evaluations of the variation in $\gamma^{\prime}$ area fraction and connectivity number in all alloy after failure. These stereological analyzes have been correlated to the number of thermal cycles up to failure in these figures and no clear alloy identification has been done in these plots in an aim to analyze in an objective way the microstructural factors controlling the TC creep resistance. It is here recalled that the connectivity number, which has been characterized using pictures taken at a 2,500X magnification, is defined as $[34,41]$ :

$$
\mathrm{Na}\left(\gamma^{\prime}\right)=\left(\mathrm{N}_{\mathrm{T}}-\mathrm{N}_{\mathrm{TP}}\right) / 2 \mathrm{~S}
$$




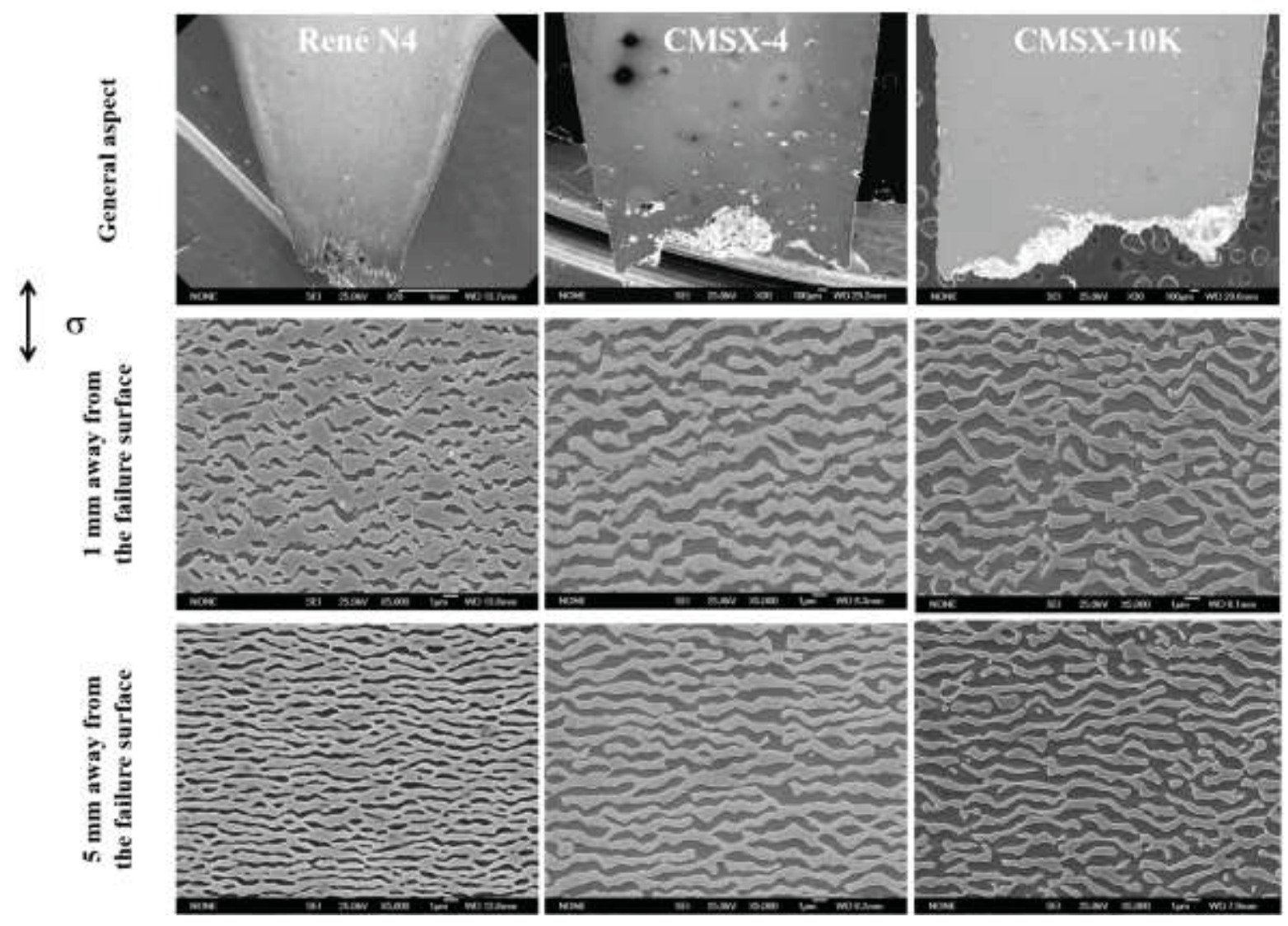

Figure 6. Microstructure observations at the end of thermal cycling creep tests for René N4, CMSX-4® and CMSX®-10K. Note that the $\gamma^{\prime}$ phase appears in dark in these pictures.

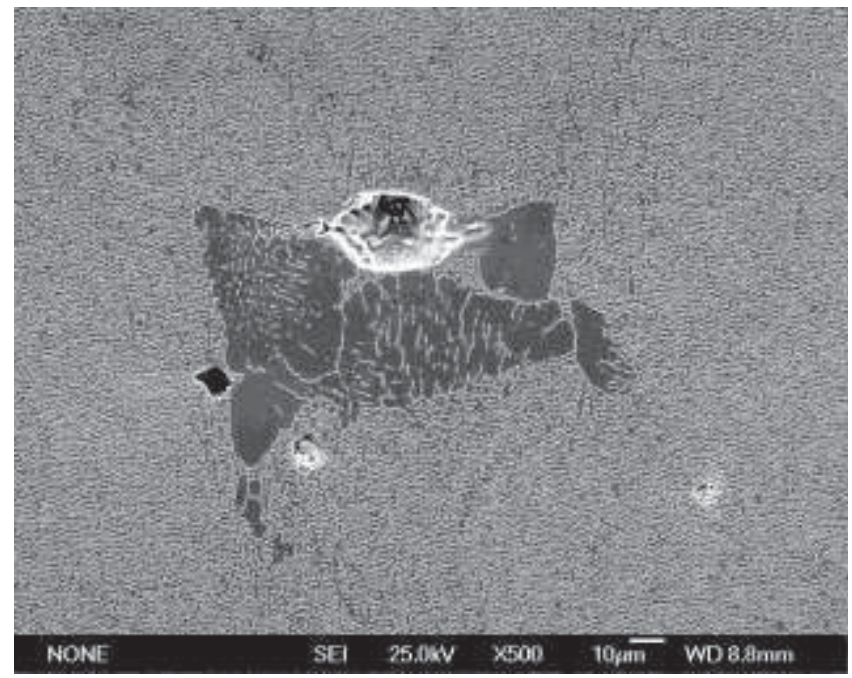

Figure 7. Example of cavitation and early stages of crack development close to a eutectic particle in CMSX®-10K.

In this equation, $\mathrm{N}_{T}$ and $\mathrm{N}_{T P}$ are respectively the number of terminations and number of triple points of the $\gamma^{\prime}$ skeleton and $\mathrm{S}$ is the area of the analyzed field [34].

According to Figure 8, it is clearly observed a better very high temperature TC creep durability with an increase of the $\gamma^{\prime}$ content. The average number of thermal cycles to failure is only 2 for a $\gamma^{\prime}$ content of $\sim 15 \%$ (case of Mar-M200 + Hf alloy) while it reaches 319 for a $\gamma^{\prime}$ content of $\sim 56 \%$ (case of CMSX ${ }^{\circledR}-10 \mathrm{~K}$ alloy). The increase in TC creep resistance is especially obvious for a $\gamma$ ' content greater than $45-50 \%$.

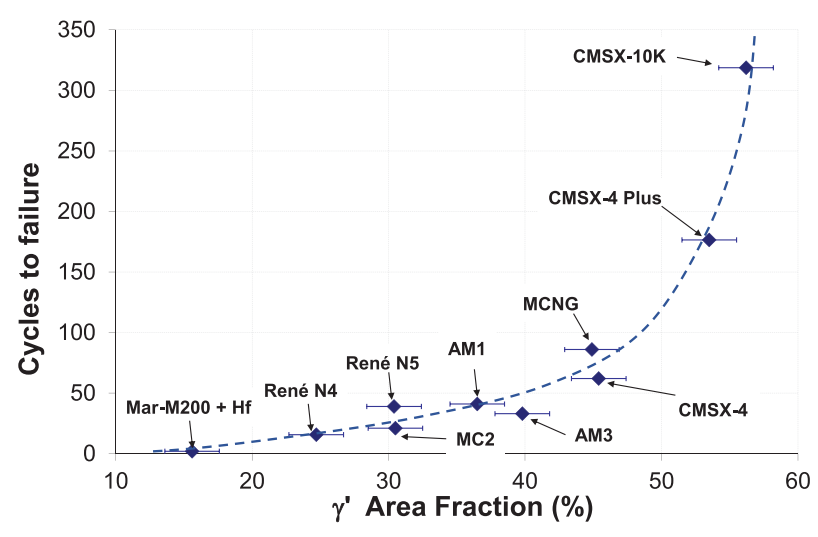

Figure 8. Evolution of the number of thermal cycles up to failure as a function of the $\gamma^{\prime}$ area fraction measured in the gage section of each sample $1 \mathrm{~mm}$ far from the fracture surface.

The evolution of the TC creep resistance follows an opposite trend with the connectivity number. It is indeed observed that alloys having a negative connectivity number (i.e. alloys in which the $\gamma / \gamma^{\prime}$ topological inversion had occurred [34, 41], namely, 
CMSX-4® Plus, CMSX ${ }^{\circledR}-10 \mathrm{~K}$ and MCNG here) have a better TC creep resistance than alloys without $\gamma / \gamma^{\prime}$ topological inversion. This is a clear indication that under such non-isothermal conditions, the progressive microstructure degradation in the form of $\gamma^{\prime}$ rafting and subsequent $\gamma^{\prime}$ platelets interconnections is not the main controlling parameter for TC creep as it is commonly considered under isothermal conditions [34, 42].

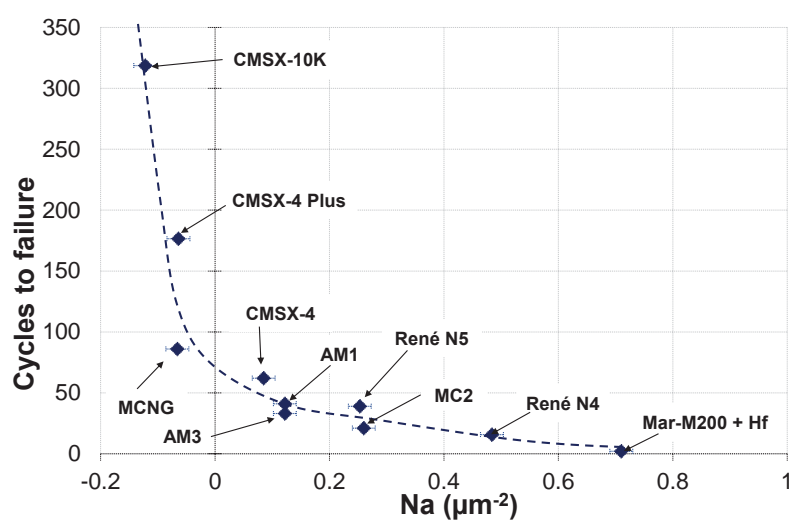

Figure 9. Evolution of the number of thermal cycles up to failure as a function of the connectivity number measured in the gage section of each sample $1 \mathrm{~mm}$ far from the fracture surface.

\section{Discussion}

\section{Analysis of the thermal cycling creep strength}

According to the previous experimental results, it is observed that the TC creep resistance at very high temperatures of Ni-based single crystal superalloys is mainly controlled by the remaining $\gamma^{\prime}$ content at high temperatures (Fig. 8). Such an analysis can be performed objectively since all specimens failed during an overheating at $1160{ }^{\circ} \mathrm{C}$. Even if failures did not occur exactly after the same duration during the last overheating, the difference in $\gamma^{\prime}$ dissolution kinetics is negligible since it has been shown by Giraud et al. that the dissolution kinetics is only temperature sensitive once a given amount of high temperature creep deformation, (nearly $0.3 \%$ in CMSX-4®), has been achieved [30]. Hence, in that case, a very good correlation between the TC creep resistance and the $\gamma^{\prime}$ volume fraction at $1160{ }^{\circ} \mathrm{C}$ is observed. This correlation can also be translated in terms of $\gamma^{\prime}$-solvus temperature. Indeed, it is observed in Fig. 10 a very good correlation between the durability in TC creep and the $\gamma^{\prime}$-solvus temperature presented in Table I. It is also noticed that the ranking in alloy's creep resistance during isothermal creep at $1160{ }^{\circ} \mathrm{C} / 120 \mathrm{MPa}$ is almost the same as that under TC conditions, clearly indicating that most of the creep damage during nonisothermal conditions is generated by temperature jumps at $1160^{\circ} \mathrm{C}$. All these results are in good agreement with past papers analysing microstructural factors contributing to the very high ( $\mathrm{T}$ $>1100^{\circ} \mathrm{C}$ ) temperature creep resistance of Ni-based single crystal superalloys and showing that under such conditions, the remaining $\gamma^{\prime}$ fraction is the main creep life controlling parameter $[4,37,43]$. Indeed, keeping a high $\gamma^{\prime}$ content at high temperature efficiently impedes the dislocation motion at high temperature by increasing both the Orowan stress $[23,44]$ and the number of $\gamma / \gamma^{\prime}$ interfaces, hence lowering the dislocation climb velocity [45].

The development of a $\gamma / \gamma^{\prime}$ topological inversion during TC creep follows previous findings of Caron et al. under isothermal conditions [34]. They showed that this microstructure evolution can only occur if the $\gamma^{\prime}$ content is over $50 \%$, what is observed experimentally in the present study for CMSX-4® Plus, CMSX ${ }^{\circledR}-10 \mathrm{~K}$ (see Figs. 8 and 9). However, the interesting result from the present study is the apparent insensitivity of the thermal cycling creep life to this $\gamma / \gamma^{\prime}$ topological inversion at very high temperatures (Fig. 9). It is indeed observed that stronger alloys in TC creep exhibit this topological inversion while it is commonly considered as a severe microstructure degradation leading to creep strain acceleration at intermediate temperatures [34, 42].

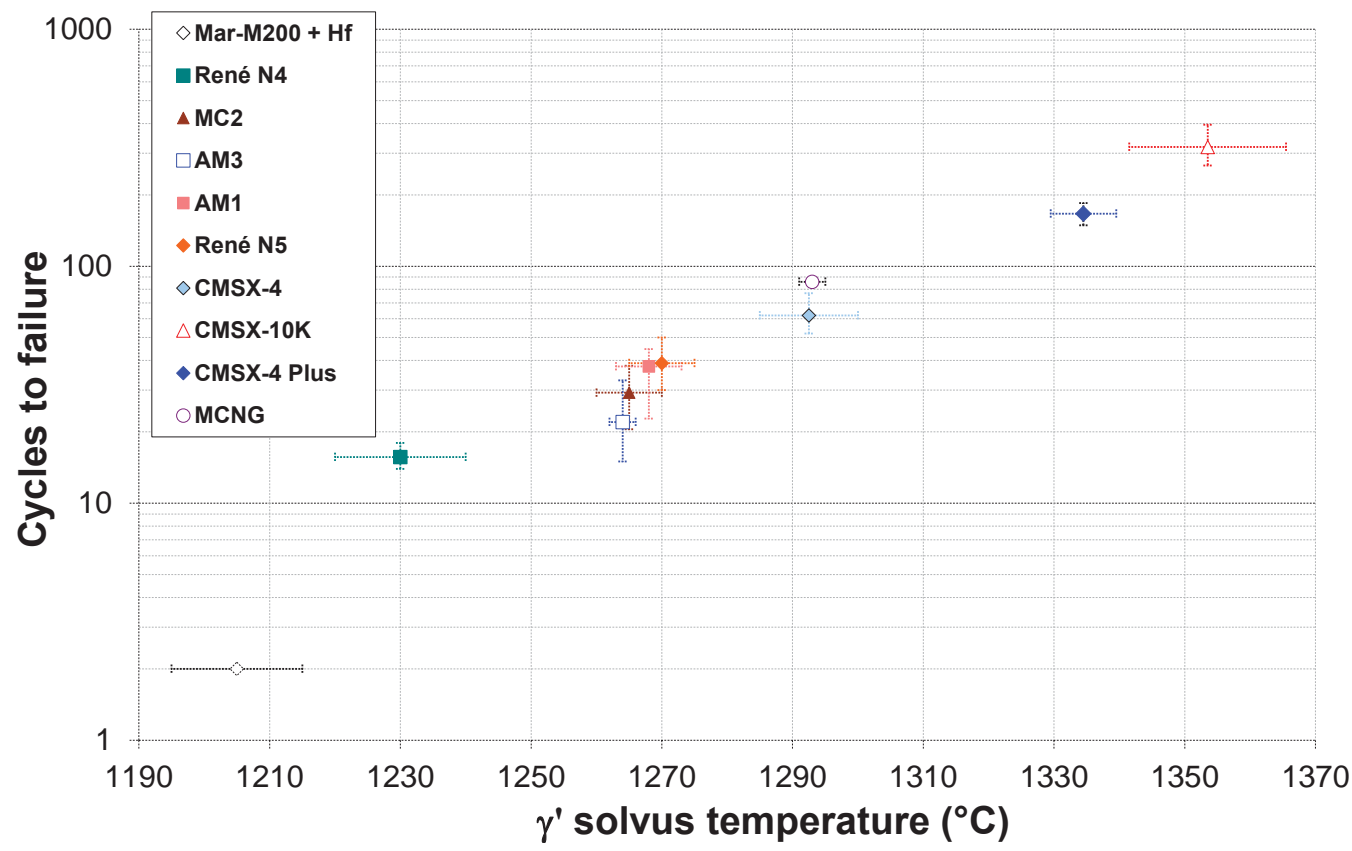

Figure 10. Correlation of the thermal cycling creep strength with the $\gamma^{\prime}$-solvus temperature. 
Normalizing the time spent at $1160{ }^{\circ} \mathrm{C} / 120 \mathrm{MPa}$ during TC creep experiments by the isothermal creep resistance at this temperature, an interesting observation occurs. It is indeed observed in Fig. 11 that strong alloys such as CMSX-4®, CMSX ${ }^{\circledR}-10 \mathrm{~K}$ and CMSX$4 ®$ Plus can resist a lower number of overheatings at $1160{ }^{\circ} \mathrm{C}$ relative to their isothermal creep resistance (between 5 to $8 \%$ ) at this temperature compared to weak alloys like Mar-M200 + Hf or René N4 (nearly $60 \%$ and $40 \%$ respectively). This can be interpreted in the following way: the non-isothermal creep resistance of Mar-M200 + Hf under these conditions is mainly controlled by its intrinsic creep resistance at $1160{ }^{\circ} \mathrm{C} / 120 \mathrm{MPa}$ (i.e. its low $\gamma^{\prime}$ content) while for alloys such as CMSX-4® Plus and $\mathrm{CMSX}{ }^{\circledR}-10 \mathrm{~K}$, the tests being longer, the microstructure degradation in the form of $\gamma^{\prime}$ rafting and $\gamma / \gamma^{\prime}$ topological inversion has enough time to take place (see Fig. 9). This $\gamma / \gamma^{\prime}$ degradation limits the number of thermal cycles the alloy can bear. Indeed, as shown by Steuer \& al. and Giraud \& al., the coarsening of the $\gamma^{\prime}$ particles and N-type $\gamma^{\prime}$ rafting are by far less TC creep resistant compared to a $\gamma / \gamma^{\prime}$ cuboidal microstructure $[23,25]$.

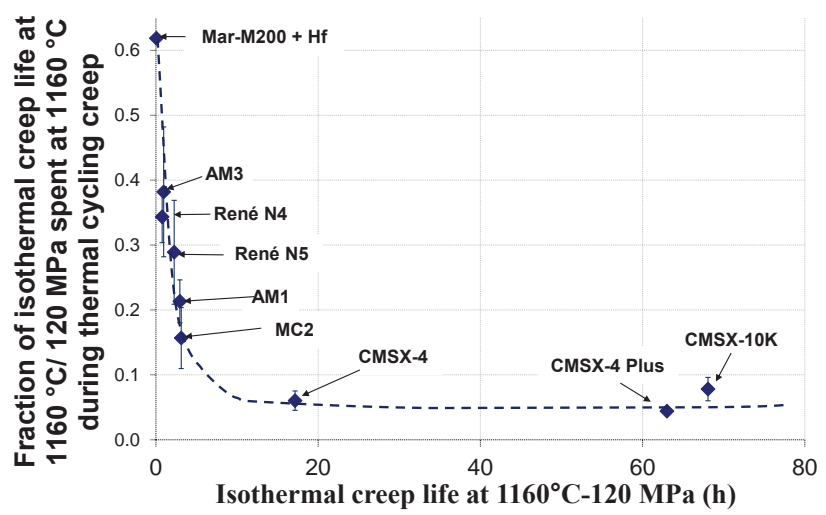

Figure 11. Fraction of time spent at $1160{ }^{\circ} \mathrm{C} / 120 \mathrm{MPa}$ during thermal cycling creep relative to the isothermal creep life plotted as a function of the isothermal creep life at $1160{ }^{\circ} \mathrm{C} / 120 \mathrm{MPa}$.

\section{Guidelines for alloys development}

According to the present analysis of the TC creep resistance, it is seen that two main guidelines have to be followed simultaneously to increase the intrinsic TC creep resistance of Ni-based single crystal superalloys:

- $\quad$ Stabilize the $\gamma^{\prime}$ phase at high temperature (i.e. maintain a high $\gamma^{\prime}$ volume fraction during overheatings).

- Limit the $\gamma^{\prime}$ degradation kinetics, such as $\gamma^{\prime}$ coarsening, N-type directional coarsening and $\gamma / \gamma^{\prime}$ topological inversion

Figure 12 shows Thermo-Calc simulations of the $\gamma^{\prime}$ volume fraction at thermodynamic equilibrium in the $1000{ }^{\circ} \mathrm{C}-1400{ }^{\circ} \mathrm{C}$ temperature range, using the TCNi8 database. Despite slight differences in $\gamma^{\prime}$ solvus temperature compared to experimental data presented in Table I for the six selected alloys presented in this figure, it is clearly observed that stronger alloys in TC creep at very high temperature have a higher $\gamma^{\prime}$ content over all the temperature domain encountered during the tests (case of CMSX$4 \AA$ Plus and $\left.\mathrm{CMSX}{ }^{\circledR}-10 \mathrm{~K}\right)$. It is pointed out that these simulations agree quite well with the fact that alloys having undergone $\gamma / \gamma^{\prime}$ topological inversion spend most of their time during TC creep experiments with a $\gamma^{\prime}$ volume fraction over $50 \%$. It is also observed that René N5, AM1 and MC2 have very similar evolutions of $\gamma^{\prime}$ content as a function of temperature in Fig. 12, in good agreement with their almost identical TC creep lives (see Fig. 10).

This first guideline, which is the most important one, can be reached by increasing the $\gamma^{\prime}$-solvus temperature, adding, e.g. rhenium, tantalum and ruthenium. In the author's opinion, adding rhenium is not necessarily the most efficient solution to increase the TC creep resistance since it is observed in Figure 13 that alloys without any rhenium (e.g. AM1, AM3, MC2) can provide comparable non-isothermal creep lives when compared with second generation alloys such as René N5. Moreover, considering rotating components such as high pressure turbine blades, the density corrected properties have to be considered. Rhenium is known to increase the density of Ni-based alloys and, as an example, it has been observed that the intrinsic advantage in TC creep life of CMSX ${ }^{\circledR}-10 \mathrm{~K}$ over CMSX-4® drops from a factor of 5.2 under same applied stress to a factor of 1.9 under same specific stress (not shown here). Finally, rhenium is also known to increase the $\gamma / \gamma^{\prime}$ lattice mismatch magnitude $[37,46]$, and hence, the $\gamma^{\prime}$-rafting kinetics. Careful adjustments in chemistry by limiting rhenium to a reasonable level (i.e. 2 wt. $\%$ at maximum) and by increasing the tantalum content are hence recommended. Adding tantalum will also lead to an increase in the intrinsic $\gamma^{\prime}$ strength to dislocation cutting, as shown by Brundidge for Tamodified René N5 [47].

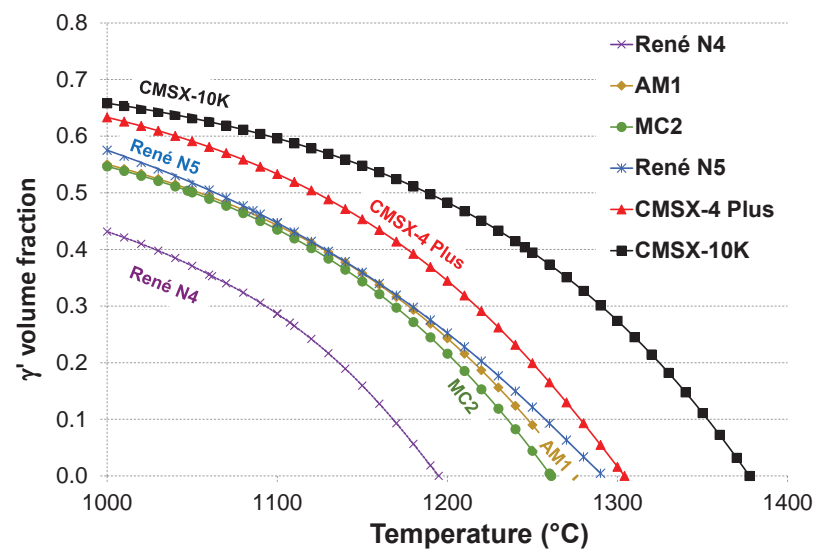

Figure 12. Thermo-Calc simulations of the $\gamma^{\prime}$ volume fraction at thermodynamic equilibrium using the TCNi8 (Ni25) database.

Considering the possibilities to retard the $\gamma^{\prime}$ degradation kinetics, one has to adjust chemistry to reduce the lattice misfit magnitude, or to design positive lattice misfit alloys. As shown by Giraud et al. a P-type rafting is efficient in reducing the average creep strain rate under tension TC creep conditions without, however, increasing the creep life [25]. Co-based alloys could have been good candidates to develop such a vertical (P-type) $\gamma^{\prime}$-rafting under high temperature creep loading and to reduce the dislocation climb kinetics [48]. However, it has to be admitted here that Co-based alloys have too low $\gamma^{\prime}$-solvus temperatures to optimize TC creep resistance [49] and more generally, limiting the $\gamma / \gamma^{\prime}$ lattice mismatch magnitude is difficult to reach having in mind the increase in $\gamma^{\prime}$-solvus temperature.

Probably, one of the most effective ways to improve both the stability of the $\gamma^{\prime}$ phase at high temperature (i.e. to keep a high $\gamma^{\prime}$ 
content and to increase the $\gamma^{\prime}$-solvus temperature), and the resistance to $\gamma^{\prime}$ coarsening would be additions of platinum. It has indeed been shown recently by Van Sluytman \& al. that adding 2.5 at. $\%$ of platinum in a second generation alloy with 1.0 at. $\%$ of rhenium clearly reduce the coarsening rate of the $\gamma^{\prime}$ phase compared to classical Ni-based alloys [50]. Moreover, it has been shown in this interesting paper that platinum mainly partitions to the $\gamma^{\prime}$ phase and stabilize the $\gamma^{\prime}$ volume fraction at very high temperature compared to Ni-based superalloys. The $\gamma^{\prime}$ content remains almost constant up to $1200{ }^{\circ} \mathrm{C}$, at a value of nearly 0.55 , a value by far greater than all Ni-based alloys studied in the present paper (see Fig. 12). Hence, adding platinum up to a reasonable content (not to alter density), seems to be a promising way to stabilize the $\gamma^{\prime}$ phase at very high temperature and further improve TC creep resistance of Ni-based single crystal superalloys.

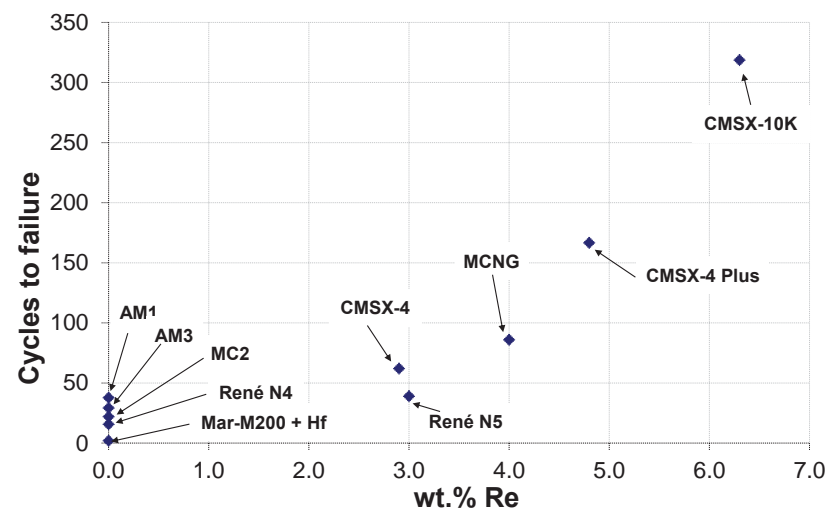

Figure 13. Thermal cycling creep resistance plotted as a function of the rhenium content.

\section{Conclusions}

The tension creep resistance under thermal cycling at very high temperature of ten different Ni-based single crystal superalloys has been investigated. Alloys from the first, second, third and fourth generations were studied. Thermal cycling creep experiments were composed of repeated short overheatings at $1105^{\circ} \mathrm{C}$ and $1160{ }^{\circ} \mathrm{C}$ in the creep life at $1050{ }^{\circ} \mathrm{C} / 120 \mathrm{MPa}$ of the alloys. From the present study, the following main conclusions can be established:

- the creep resistance under such non-isothermal conditions is primarily controlled by the remaining $\gamma^{\prime}$ volume fraction at high temperature, especially during temperature spikes at $1160{ }^{\circ} \mathrm{C}$.

- $\quad$ even if no direct correlation is observed between the thermal cycling creep durability and the microstructure degradation (i.e. N-type directional coarsening, $\gamma / \gamma^{\prime}$ topological inversion), it was observed that strong alloys during thermal cycling creep can survive less temperature overheatings at $1160{ }^{\circ} \mathrm{C}$ relative to their isothermal creep life at this temperature. This results from the longer test duration, allowing $\gamma^{\prime}$-rafting and/or $\gamma / \gamma^{\prime}$ topological inversion to occur.

From the present study, some guidelines are proposed to develop alloys with higher thermal cycling creep resistance.

\section{Acknowledgements}

All this work would have never been possible without the long term collaboration developed with SAFRAN-Turbomeca on this topic. Dr. Zéline Hervier, Dr. François Vogel, Dr. Antoine Organista and Samuel Thabart (both at the Materials Department of Safran-Turomeca) are gratefully acknowledged for continuous interest in this study and for providing AM3, MC2 and MCNG samples. Dr. Ken Harris and Dr. Jacqueline Wahl from Cannon Muskegon Corporation (a PCC company) are gratefully acknowledged for providing CMSX-4®, CMSX-4® Plus and CMSX ${ }^{\circledR}-10 \mathrm{~K}$ bars, DSC results and for their deep interest in this study. Dr. Akane Suzuki (GE Global Research) is acknowledged for providing René N4 and René N5 plates and for fruitful discussions. SAFRAN-Snecma is acknowledged for providing AM1 and Mar-M200 + Hf materials. Discussions with Dr. Pierre Caron (ONERA) and Professor Tresa Pollock (University of California - Santa Barbara) were highly appreciated. The author is grateful to Dr. Coraline Crozet and Dr. Alexandre Devaux (Aubert et Duval, Les Ancizes) for providing Thermo-Calc simulations and for fruitful discussions. Technical assistance from Florence Hamon (Institut Pprime), Dr. Susanne Steuer (former Post-doc student at Institut Pprime and Materials Department of UCSB), Dr. Rémi Giraud (former PhD student at Institut Pprime and SAFRAN Turbomeca) and Lorena Mataveli Suave (PhD student at Institut Pprime and SAFRAN Technology and Research Center) is gratefully acknowledged. Finally, the author is indebted to Dr. José Mendez (Emeritus CNRS director of research at Institut Pprime) for having facilitated the growth of superalloys activities at Institut Pprime and for all stimulating discussions.

\section{References}

1. T.M. Pollock and S. Tin, "Nickel-Based Superalloys for Advanced Turbine Engines: Chemistry, Microstructure, and Properties", Journal of Propulsion and Power, 22 (2) (2006), 361-374.

2. K. Kawagishi et al. "Development of an Oxidation-Resistant High-Strength Sixth-Generation Single-Crystal Superalloy TMS238", (Paper presented at Superalloys 2012, Seven Springs, PA, USA, 2012), 189-195.

3. Y. Koizumi et al. "Development of next-generation Ni-base single crystal superalloys", (Paper presented at Superalloys 2004, 2004), 35-43.

4. R.C. Reed, The Superalloys - Fundamentals and Applications (Cambridge, UK: Cambridge University Press, 2006).

5. J. Cormier et al. "Non-isothermal creep behavior of a second generation Ni-based single crystal superalloy: experimental characterization and modeling", (Paper presented at Superalloys 2008, Seven Springs, Champion, PA, USA, 2008), 941-949.

6. F. Mauget et al. "Development and use of a new burner rig facility to mimic service loading conditions of Ni-based single crystal superalloys", (Paper presented at Eurosuperalloys 2014, Presqu'île de Giens, France, 2014), 20001. 
7. J.-B. le Graverend et al., "Highly non-linear creep life induced by a short close $\gamma^{\prime}$-solvus overheating and a prior microstructure degradation on a nickel-based single crystal superalloy", Materials and Design, 56 (April) (2014), 990-997.

8. J. Cormier, X. Milhet, and J. Mendez, "Anisothermal Creep at very high temperature of a second generation Ni-based single crystal superalloy", Materials Science and Engineering A, 483484 (2008), 594-597.

9. J. Cormier et al., "Simulation of very high temperature overheating during isothermal creep of single crystal Ni-base superalloy", Advanced Engineering Materials, 10 (1-2) (2008), 56-61.

10. J. Cormier, X. Milhet, and J. Mendez, "Non-isothermal creep at very high temperature of the Nickel based single crystal superalloy MC2", Acta Materialia, 55 (18) (2007), 6250-6259.

11. J.P. Rowe and J.W. Freeman, Effect of overheating on the creep-rupture properties of HS-31 alloy, 1 June 1956 51, University of Michigan, Engineering Research Institute, 1956.

12. J.P. Rowe and J.W. Freeman, Effect of overheating on creeprupture properties of S-816 alloy at $1,500^{\circ} \mathrm{F}$, NACA Technical Note 4081, University of Michigan, 1957.

13. J.P. Rowe and J.W. Freeman, Effect of overheating on creeprupture properties of HS-31 alloy at $1,500^{\circ} \mathrm{F}$, NACA Technical Note 4083, University of Michigan, 1957.

14. J.P. Rowe and J.W. Freeman, Effect of overheating on creeprupture properties of M-252 alloy, NACA Technical Note 4224, University of Michigan, 1958.

15. J.P. Rowe and J.W. Freeman, Effect of overheating on the creep-rupture properties of M252 and Inconel 700at $1500^{\circ}$ and $1600^{\circ} \mathrm{F}$, 25 March 1960 University of Michigan, Engineering Research Institute, 1960.

16. I. Weiss, A. Rosen, and G. Brandon, "Creep of Udimet 500 during thermal cycling: I. The minimum creep rate", Metallurgical Transactions, 6A (1975), 761-766.

17. I. Weiss, A. Rosen, and G. Brandon, "Creep of Udimet 500 during thermal cycling: II. The time to failure", Metallurgical Transactions, 6A (1975), 767-772.

18. R. Goti, B. Viguier, and F. Crabos. "Effect of thermal cycling on high temperature creep of coated CMSX-4", (Paper presented at Superalloys 2012, Seven Springs, PA, USA, 2012), 411-419.

19. A. Raffaitin et al., "The effect of thermal cycling on the hightemperature creep behaviour of a single crystal nickel-based superalloy", Scripta Materiala, 56 (2007), 277-280.

20. F. Touratier et al., "Dislocation mechanisms during high temperature creep experiments on MC2 alloy", Advanced Materials Research, 278 (2011), 7-12.
21. B. Viguier, F. Touratier, and E. Andrieu, "High-temperature creep of single-crystal nickel-based superalloy: microstructural changes and effects of thermal cycling", Philosphical Magazine, 91 (35) (2011), 4427-4446.

22. J.-B. le Graverend et al., "Creep of a nickel-based single crystal superalloy during very high temperature jumps followed by synchrotron X-Ray diffraction", Acta Materialia, 84 (2015), 65-79.

23. S. Steuer et al., "Creep behavior under isothermal and nonisothermal conditions of AM3 single crystal superalloy for different solutioning cooling rates", Material Science and Engineering A, 601 (2014), 145-152.

24. J.-B. le Graverend et al., "In situ measurement of the $\gamma / \gamma^{\prime}$ lattice mismatch evolution of a nickel-based single crystal superalloy during non-isothermal very high temperature creep experiments", Metallurgical and Materials Transactions A, 43A (2012), 3946-3951.

25. R. Giraud et al. "Effect of the prior microstructure degradation on the high temperature/low stress non-isothermal creep behavior of CMSX-4® Ni-based single crystal superalloy", (Paper presented at Superalloys 2012, Seven Springs, PA, USA, 2012), $265-274$.

26. J. Ghighi et al., "A Microstructure Sensitive Approach for the Prediction of the Creep Behaviour and Life under Complex Loading Paths", Technische Mechanik, 32 (2-5) (2012), 205-220.

27. J.-B. le Graverend et al., "Effect of fine $\gamma^{\prime}$ precipitation on non-isothermal creep and creep-fatigue behaviour of nickel base superalloy MC2", Materials Science and Engineering A, 527 (20) (2010), 5295-5302.

28. J. Cormier et al., "Very high temperature creep behavior of a single crystal Ni-based superalloy under complex thermal cycling conditions", Philosophical Magazine Letters, 90 (8) (2010), 611620 .

29. J. Cormier and G. Cailletaud, "Constitutive modeling of the creep behavior of single crystal superalloys under non-isothermal conditions inducing phase transformations", Materials Science and Engineering A, 527 (23) (2010), 6300-6312.

30. R. Giraud et al., "Strain effect on the $\gamma^{\prime}$ dissolution at very high temperatures of a nickel-based single crystal superalloy", Metallurgical and Materials Transactions A, 44A (2013), 131146.

31. K. Harris and J.B. Wahl, High strength single crystal nickel based superalloy, in European Patent Office. 2015, EP 2942411 A1: Europe.

32. J. Wahl and K. Harris. "CMSX-4® Plus Single Crystal Alloy Development, Characterization and Application Development", (Paper presented at Superalloys 2016, Seven Springs, PA, USA, 2016). 
33. J.R. Vaunois et al. "Influence of both $\gamma^{\prime}$ distribution and grain size on the tensile properties of UDIMET $720 \mathrm{Li}$ at room temperature", (Paper presented at 7th International Symposium on Superalloy 718 and Derivatives, Pittsburgh, PA, USA, 2010), 199-213.

34. P. Caron, C. Ramusat, and F. Diologent. "Influence of the $\gamma^{\prime}$ fraction on the topological inversion during high temperature creep of single crystal superalloys", (Paper presented at Superalloys, Seven Springs, Champion, PA, USA, 2008), 159167.

35. G.E. Fuchs and B.A. Boutwell, "Calculating Solidification and Transformation in As-Cast CMSX-10", JOM, (January) (2002), $45-48$.

36. J.J. Jackson et al., "The effects of volume percent of fine $\gamma^{\prime}$ on creep in DS Mar-M200 + Hf", Metallurgical Transactions, 8A (October) (1977), 1615-1620.

37. P. Caron. "High $\gamma^{\prime}$ solvus new generation nickel-based superalloys for single crystal turbine blade applications", (Paper presented at Superalloys 2000, Seven Springs, PA, USA, 2000), 737-746.

38. F. Diologent, "Comportement en fluage et en traction de superalliages monocristallins à base de nickel", (Ph.D. thesis, Université de Paris Sud, Centre d'Orsay, France, 2002).

39. J. Cormier, X. Milhet, and J. Mendez, "Effect of very high temperature short exposures on the dissolution of the $\gamma^{\prime}$ phase in single crystal MC2 superalloy", Journal of Materials Science, 42 (18) (2007), 7780-7786.

40. R.C. Reed, D.C. Cox, and C.M.F. Rae, "Damage accumulation during creep deformation of a single crystal superalloy at $1150^{\circ} \mathrm{C} "$, Materials Science and Engineering A, 448 (2007), 88-96.

41. A. Fredholm and J.L. Strudel. "High temperature creep mechanisms in single crystals of some high performance nickel base superalloys", (Paper presented at Petten International Conference, London, U.K., 1987), 9-18.

42. A. Epishin et al., "Kinetics of the topological inversion of the $\gamma / \gamma^{\prime}$ microstructure during creep of a nickel-based superalloy", Acta Materialia, 49 (2001), 4017-4023.

43. T. Murakumo et al., "Creep behaviour of Ni-base singlecrystal superalloys with various $\gamma^{\prime}$ volume fraction", Acta Materialia, 52 (2004), 3737-3744.

44. T.M. Pollock and A.S. Argon, "Creep resistance of CMSX-3 nickel base superalloy single crystals", Acta Metallurgica Materialia, 40 (1) (1992), 1-30.

45. H. Mughrabi and U. Tetzlaff, "Microstructure and hightemperature strength of monocrystalline nickel-base superalloys", Advanced Engineering Materials, 2 (6) (2000), 319-326.

46. A. Heckl et al., "The effect of $\mathrm{Re}$ and $\mathrm{Ru}$ on $\gamma / \gamma^{\prime}$ microstructure, $\gamma$-solid solution strengthening and creep strength in nickel-base superalloys", Materials Science and Engineering A, 528 (2011), 3435-3444.

47. C.L. Brundidge, "Development of a processing-structurefatigue property model for single crystal superalloys", (Ph.D. thesis, University of Michigan, USA, 2011).

48. H. Mughrabi, "The importance of sign and magnitude of $\gamma / \gamma^{\prime}$ lattice misfit in superalloys - with special reference to the new $\gamma^{\prime}$ hardened cobalt-base superalloys", Acta Materialia, 81 (2014), 21-29.

49. S.K. Makineni et al., "A new class of high strength high temperature Cobalt based $\gamma-\gamma^{\prime} \mathrm{Co}-\mathrm{Mo}-\mathrm{Al}$ alloys stabilized with Ta addition", Acta Materiala, 97 (2015), 29-40.

50. J.S. Van Sluytman, C.J. Moceri, and T.M. Pollock, "A Ptmodified Ni-base superalloy with high temperature precipitate stability", Material Science and Engineering A, 639 (2015), 747754. 